\begin{tabular}{|c|l|}
\hline Title & Nickel-Catalyzed -Carboxylation of Y namides with Carbon Dioxide \\
\hline Author(s) & Doi, Ryohei; Okano, Taichi; A bdullah, Iman; Sato, Y oshihiro \\
\hline Citation & $\begin{array}{l}\text { Synlett, 30(9), 1048_1052 } \\
\text { https://doi.org/10.1055/s0037-1611529 }\end{array}$ \\
\hline Issue Date & 2019-06 \\
\hline Doc URL & http://hdl.handle.net/2115/78775 \\
\hline Type & article(author version) \\
\hline File Information & Wos_89680_Doi.pdf \\
\hline
\end{tabular}

Instructions for use 


\section{Nickel-Catalyzed $\beta$-Carboxylation of Ynamides with Carbon Dioxide}

\author{
Ryohei Doia \\ Taichi Okano ${ }^{a}$ \\ Iman Abdullah \\ Yoshihiro Sato*a \\ a Faculty of Pharmaceutical Sciences, Hokkaido University, \\ Sapporo 060-0812, Japan \\ b Current position: Department of Chemistry, Faculty of \\ Mathematic and Natural Sciences, Universitas Indonesia, \\ Depok 16424, Indonesia \\ * indicates the main/corresponding author. \\ biyo@pharm.hokudai.ac.jp
}

Click here to insert a dedication<smiles>[R]C#CN([13CH3])[13CH]C[13CH2][13CH2][13CH]</smiles>

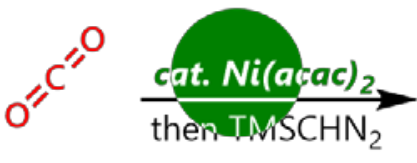

\author{
$\beta$ - and syn-Selective \\ Hydrocarboxylation
}<smiles>[R]/C(=C\C(=O)OC)N([13CH3])[13CH3]</smiles>

14 Examples

Up to $78 \%$ Yield

\section{Received:
Accepted:
Published online:}

Abstract: Described herein is nickel-catalyzed $\beta$-selective hydrocarboxylation of ynamide to obtain protected dehydro- $\beta$-amino acids. The key to exclusive $\beta$ selectivity is the use of diethylzinc as a reductant in the presence of a magnesium salt. The reaction was conducted with $\mathrm{Ni}(\mathrm{acac})_{2}$ instead of costly and sensitive $\mathrm{Ni}(\mathrm{cod})_{2}$. In addition, the optimized ligand was inexpensive 1,5cyclooctadiene. Investigation of the substrate scope revealed that both nitrogen and alkyne substituents have considerable influence on the reaction efficiency. We obtained experimental clues that indicated the formation of a vinylzinc intermediate forging a $\mathrm{C}-\mathrm{C}$ bond with $\mathrm{CO}_{2}$.

Key words Ynamide, Hydrocarboxylation, Carbon Dioxide, Nickel catalysis, $\beta$ Amino Acid

Carbon dioxide $\left(\mathrm{CO}_{2}\right)$ is an attractive $\mathrm{C}-1$ building block because of its inexpensiveness, low toxicity and easy manipulation. However, chemical transformation of $\mathrm{CO}_{2}$ is hampered by its low reactivity, which traditionally requires harsh conditions or a strong nucleophile such as organolithium or Grignard reagent for $\mathrm{C}-\mathrm{C}$ bond construction. Recently, a transition-metal complex have played an important role for dramatic improvement of this chemistry; a variety of unique, mild and chemoselective carboxylation reactions using $\mathrm{CO}_{2}$ have been developed under transition-metal catalysis. ${ }^{1}$ Nickel catalysts have been used for carboxylation of unsaturated $\mathrm{C}-\mathrm{C}$ bonds such as alkyne, ${ }^{2}$ alkene ${ }^{3} 1,2$ - and 1,3 -dienes, ${ }^{4}$ which are not able to forge a $\mathrm{C}-\mathrm{C}$ bond with $\mathrm{CO}_{2}$ in the absence of a catalyst due to their poor nucleophilicity.

In this context, we have been engaged in carboxylation of ynamides for synthesis of amino acid derivatives because of their importance as biologically active molecules..$^{5-7}$ Consequently, we have reported nickel-mediated hydrocarboxylation of ynamides using $\mathrm{CO}_{2}$ (Scheme 1a). ${ }^{2 a}$ The polarity of a $\mathrm{C}-\mathrm{C}$ triple bond of ynamide allowed the oxidative cyclization process with $\mathrm{CO}_{2}$ and $\mathrm{Ni}(0)$ to occur in a regioselective manner to yield a $\beta$ carboxylation product exclusively. ${ }^{8}$ It is noteworthy that Rhcatalyzed enantioselective hydrogenation of the products enabled access to chiral $\beta$-amino acids. ${ }^{2 a}$ Our next challenge was directed toward establishment of a catalytic carboxylation to bypass the cost and troublesome instability of $\mathrm{Ni}(\operatorname{cod})_{2 .} .^{9}$ We succeeded in developing Ni-catalyzed hydrocarboxylation of ynamide by use of $\mathrm{Zn}$ as a reductant and water as a hydrogen source. $^{2 b}$ Interestingly, the reaction gave an $\alpha$-carboxylated compound as a major product despite the polarity of an ynamide C-C triple bond, which favors coupling with electrophile at the $\beta$ position (Scheme 1b). Herein, we describe nickel-catalyzed $\beta$ selective hydrocarboxylation of ynamides with $\mathrm{CO}_{2}$ (Scheme 1c). Catalytic reactions worked well with the use of $\mathrm{Ni}(\mathrm{II})$ salt instead of sensitive $\mathrm{Ni}(\operatorname{cod})_{2}$ and costly phosphine- or nitrogen-based ligands.

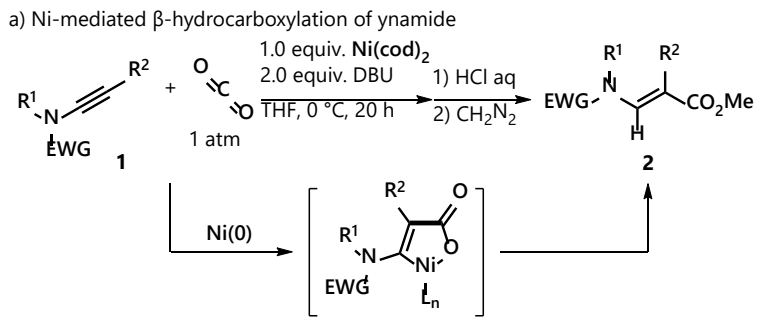

b) Ni-catalyzed $\alpha$-hydrocarboxylation of ynamide
$\begin{aligned} & 10 \mathrm{~mol} \% \mathrm{Ni}(\mathrm{cod})_{2} \\ & 10 \mathrm{~mol} \% \text { bpy } \\ & 3 \text { equiv. } \mathrm{Zn} / \mathrm{MgBr}_{2}\end{aligned}$
$\begin{aligned} & 1 \mathrm{~atm} \mathrm{CO}_{2}, 0.5 \text { equiv. } \mathrm{H}_{2} \mathrm{O} \\ & \mathrm{DMF}, 0^{\circ} \mathrm{C}_{1}, 12 \mathrm{~h} \text {; } \\ & \text { then, 1) } \mathrm{HCl} \text { aq, 2) } \mathrm{CH}_{2} \mathrm{~N}_{2}\end{aligned}$

c) This work: Ni-catalyzed $\beta$-hydrocarboxylation of ynamide

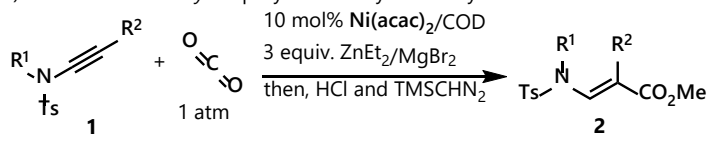

Scheme 1. Ni-mediated or -catalyzed hydrocarboxylation of ynamides 
Table 1. Condition Screening

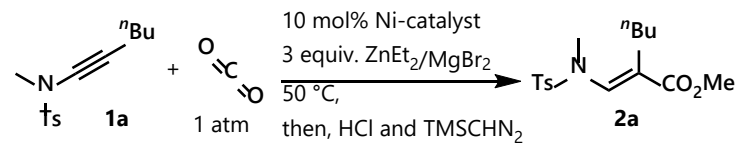

\begin{tabular}{|c|c|c|c|c|c|}
\hline Run & Catalyst & Solv. & Time & Conc. & Yield $^{a}$ \\
\hline $1^{b}$ & $\mathrm{Ni}(\operatorname{cod})_{2} / \mathrm{bpy}$ & DMF & $12 \mathrm{~h}$ & $0.2 \mathrm{M}$ & $46 \%$ \\
\hline $2^{b}$ & $\mathrm{Ni}(\operatorname{cod})_{2} /$ tmeda & DMF & $12 \mathrm{~h}$ & $0.2 \mathrm{M}$ & $45 \%$ \\
\hline $3^{b}$ & $\mathrm{Ni}(\operatorname{cod})_{2} / \mathrm{PPh}_{3}$ & DMF & $12 \mathrm{~h}$ & $0.2 \mathrm{M}$ & $30 \%$ \\
\hline $4^{b}$ & $\mathrm{Ni}(\operatorname{cod})_{2}$ & DMF & $12 \mathrm{~h}$ & $0.2 \mathrm{M}$ & $47 \%$ \\
\hline $5^{b, c}$ & $\mathrm{Ni}(\operatorname{cod})_{2}$ & DMF & $12 \mathrm{~h}$ & $0.2 \mathrm{M}$ & $15 \%$ \\
\hline 6 & $\mathrm{Ni}(\operatorname{cod})_{2}$ & DMF & $12 \mathrm{~h}$ & $0.1 \mathrm{M}$ & $55 \%$ \\
\hline 7 & $\mathrm{Ni}(\text { acac })_{2}$ & DMF & $12 \mathrm{~h}$ & $0.1 \mathrm{M}$ & $27 \%$ \\
\hline $8^{d}$ & $\mathrm{Ni}(\mathrm{acac})_{2}$ & DMF & $1 \mathrm{~h}$ & $0.1 \mathrm{M}$ & $58 \%^{g}$ \\
\hline $9 e$ & $\mathrm{Ni}(\text { acac })_{2}$ & DMF & $1 \mathrm{~h}$ & $0.1 \mathrm{M}$ & $60 \%$ \\
\hline $10^{f}$ & $\mathrm{Ni}(\text { acac })_{2}$ & DMF & $1 \mathrm{~h}$ & $0.1 \mathrm{M}$ & $26 \%$ \\
\hline $11^{d}$ & $\mathrm{Ni}(\text { acac })_{2}$ & DMPU & $1 \mathrm{~h}$ & $0.1 \mathrm{M}$ & $66 \%{ }^{g}$ \\
\hline $12^{d}$ & $\mathrm{Ni}(\text { acac })_{2}$ & NMP & $1 \mathrm{~h}$ & $0.1 \mathrm{M}$ & $68 \%^{g}$ \\
\hline $13^{d}$ & $\mathrm{Ni}(\text { acac })_{2}$ & DMA & $1 \mathrm{~h}$ & $0.1 \mathrm{M}$ & $63 \%^{g}$ \\
\hline $14^{d}$ & $\mathrm{Ni}(\text { acac })_{2}$ & $\mathrm{MeCN}$ & $1 \mathrm{~h}$ & $0.1 \mathrm{M}$ & $4 \%$ \\
\hline
\end{tabular}

${ }^{a}$ NMR yield. ${ }^{b}$ Methylated with $\mathrm{CH}_{2} \mathrm{~N}_{2}$. ${ }^{c}$ Without $\mathrm{MgBr}_{2} .{ }^{d}$ With 1 equiv. COD. ${ }^{e}$ With 1 equiv. NBD. fWith 1 equiv. cis-4-octene. gIsolated yield.

We commenced investigation by using diethylzinc instead of a zinc/water reductant system, which we used in our previous study, ${ }^{2 \mathrm{~b}}$ for catalytic turn-over of active nickel species. As a result, $\beta$-carboxylation product $2 \mathrm{a}$ was obtained in $46 \%$ yield with $10 \mathrm{~mol} \% \mathrm{Ni}(\operatorname{cod})_{2}$ accompanied by a small quantity ( $<1 \%$ yield) of the $\alpha$-carboxylation product (Table 1 , run 1 ). Interestingly, we found that the reaction was not significantly affected by the addition of an auxiliary ligand such as 2,2'bipyridine (bpy), $\mathrm{N}, \mathrm{N}, \mathrm{N}, \mathrm{N}$-tetramethylethylenediamine (tmeda) or $\mathrm{PPh}_{3}$ (runs 1-4). In contrast to ligands, the addition of magnesium salt was found to be indispensable (run 5). A lower concentration gave a better yield (run 6). We assumed that 1,5cyclooctadiene (COD) is working as a suitable stabilizer of a nickel catalyst in run 4 . Then, to circumvent the use of highly sensitive $\mathrm{Ni}(\operatorname{cod})_{2}$, we tested the use of $\mathrm{Ni}(\text { acac })_{2}$, which would be reduced to $\mathrm{Ni}(0)$ by the action of diethylzinc, and we confirmed that the desired product was isolated in $58 \%$ yield in the presence of COD (runs 7,8). In this case, TLC analysis indicated that consumption of the starting material was completed within $1 \mathrm{~h}$. The addition of norbornadiene (NBD) was also effective, while cis-4-octene was not a suitable olefin for assisting the nickel catalysis (runs 9,10). Finally, we evaluated several polar solvents in our carboxylation reaction. Reactions in $N, N^{\prime}$ dimethylpropyleneurea (DMPU) or 1-methyl-2-pyrrolidone (NMP) gave better results than reactions carried out in DMF and DMA (runs 11-13). Acetonitrile was an inappropriate solvent for our system (run 14). NMP gave a better isolated yield due to the ease of chromatographic purification.

We next investigated the substrate scope of our $\beta$ selective carboxylation reaction. First, we studied the effect of nitrogen substituents (Table 2). By comparing ynamides having Ts (1a) and mesyl (Ms, 1b), Ts-ynamide gave a better result. The reaction of an ynamide $\mathbf{1 c}$ having an oxazolidinone ring gave the desired product in $28 \%$ yield. Unfortunately, a crude mixture containing 2c did not allow chromatographic separation from the by-products. The reaction of acyclic carbamate $1 \mathbf{d}$ also worked, but the yield was low. We next screened a partner of the Ts group on nitrogen. Ynamide 1e protected by a benzyl group delivered the desired product in $65 \%$ yield. We found that ynamide $1 \mathrm{f}$ having a Ts and a cyclohexyl group gave the desired product $\mathbf{2} \mathbf{f}$ in $79 \%$ yield. We then focused on a bulky and removable protecting group for a synthetic advantage. Hydrocarboxylation with a Tsynamide $\mathbf{2 g}$ decorated with a diphenylmethyl group resulted in a low yield even with prolonged reaction time. We then used a tertbutyl group, which is known to be deprotected under acidic conditions, to afford the desired product $2 \mathbf{h}$ in $78 \%$ yield.

Table 2. Effect of nitrogen substitution ${ }^{a}$

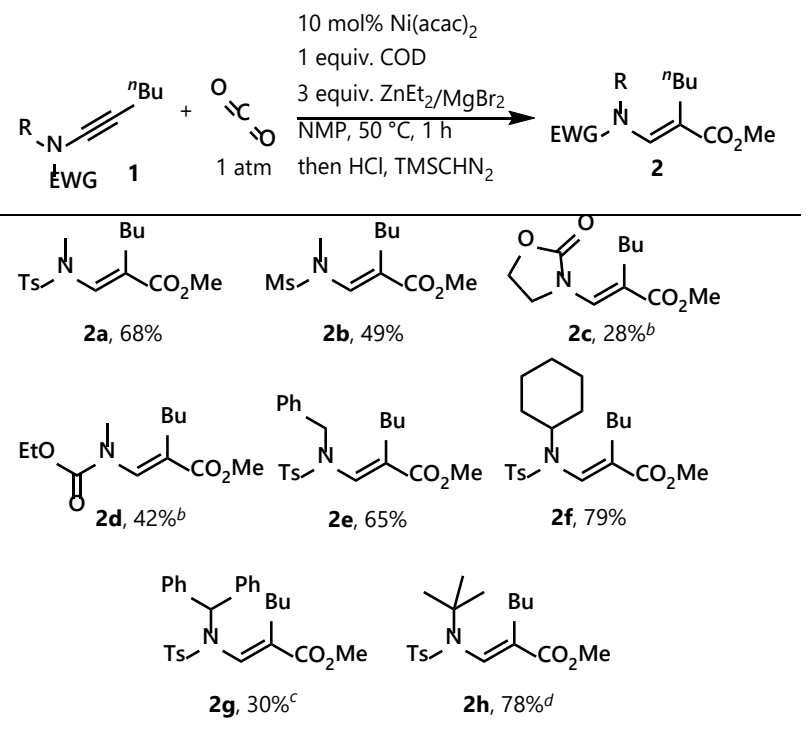

${ }^{a}$ Isolated yield. ${ }^{b} \mathrm{NMR}$ yield. ${ }^{c} 24 \mathrm{~h} .{ }^{d} 2 \mathrm{~h}$.

By using ynamides protected with Ts and a tert-butyl group, we examined the scope of a substituent on an alkyne moiety (Table 3 ). Reactions of ynamides carrying primary alkyl groups resulted in good yields $(\mathbf{2} \mathbf{i}, \mathbf{2} \mathbf{j})$. In contrast, carboxylation of an ynamide having a secondary alkyl group was sluggish, probably due to steric congestion between $Z$-olefin substituents. In fact, an isopropyl ynamide carrying a methyl group on nitrogen gave the desired product $\mathbf{2 k}$ albeit in low yield. Ynamides derived from phenylacetylene gave the desired product 21 in $54 \%$ yield. The reactions of $\mathbf{1 m}$ and $1 \mathrm{n}$ having a 3-fluoro group and a 4-anisyl group proceeded to give the compounds $\mathbf{2 m}$ and $\mathbf{2 n}$ in $63 \%$ and $67 \%$ yields, respectively. The structure of $\mathbf{2 n}$ was confirmed by $\mathrm{X}$-ray crystallography (Figure 1).10 
Table 3. Effect of alkyne terminus

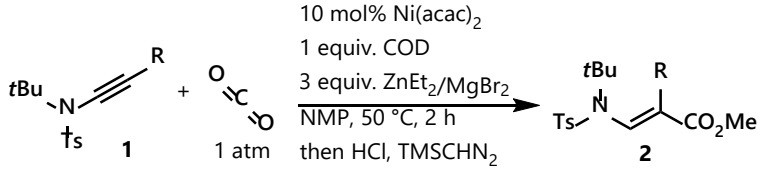

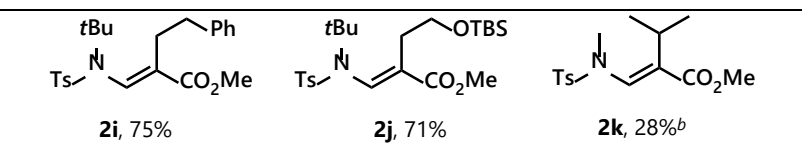

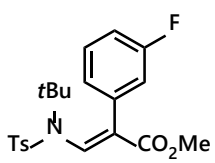

${ }^{a}$ Isolated yields were shown. ${ }^{b}$ Yield determined by ${ }^{1} \mathrm{H}$ NMR analysis.

Figure 1. Structure of $\mathbf{2 n}$

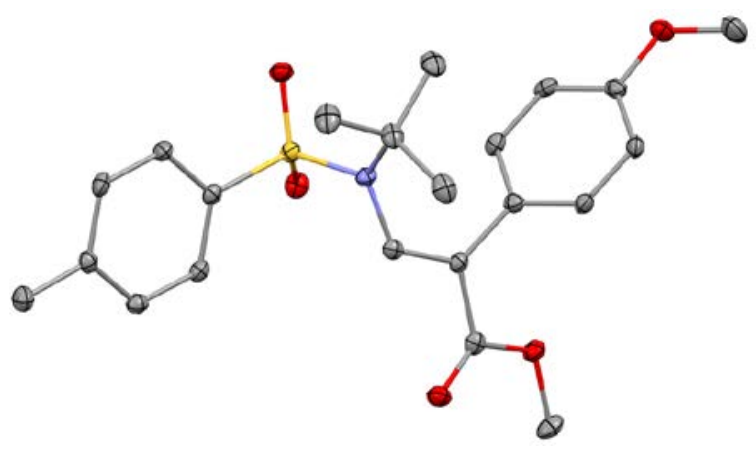

The displacement ellipsoids for one of two molecules in a lattice are drawn at $50 \%$ probability level. Hydrogen atoms were omitted for clarity.

Scheme 2. Scale-up reaction and transformation of the product.

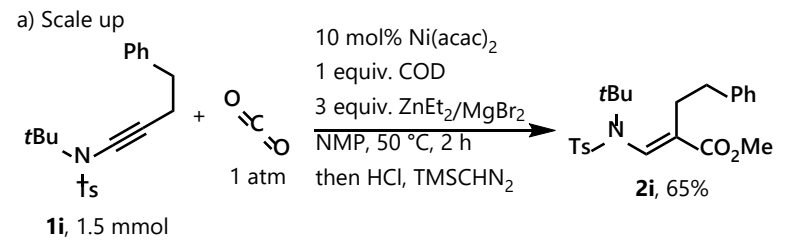

b) Deprotection of $\mathbf{2 i}$

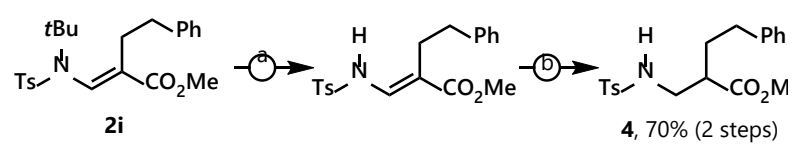

Conditions for transformation: a) $\mathrm{Et}_{2} \mathrm{O} / \mathrm{HCl}, \mathrm{rt}$; b) $\mathrm{Pd} / \mathrm{C}, \mathrm{H}_{2}$, $\mathrm{MeOH}, \mathrm{rt}$.

Our reaction could be performed on a $1.5 \mathrm{mmol}$ scale (Scheme 2a). To demonstrate the application of our reaction, we studied deprotection of a tert-Bu group on nitrogen. Treatment of $\mathbf{2} \mathbf{i}$ with
$\mathrm{HCl}$ in ether gave an unstable deprotected enamine that was subsequently reduced into the amino acid $\mathbf{4}$ under an $\mathrm{H}_{2}$ atmosphere with $\mathrm{Pd} / \mathrm{C}$. It is noteworthy that an attempt to reduce 2i with $\mathrm{Pd} / \mathrm{C}$ under $\mathrm{H}_{2}$ was unsuccessful, probably due to steric hindrance of the tert-Bu group on nitrogen.

Figure 2. Mechanistic study and proposed mechanism

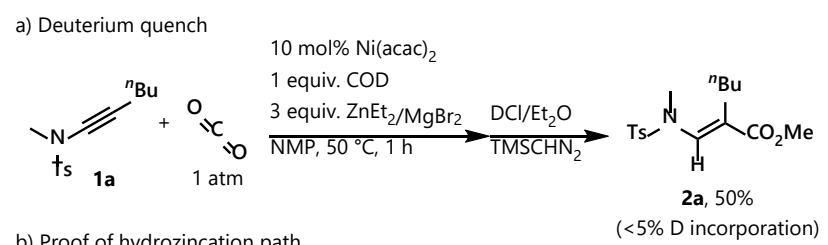

b) Proof of hydrozincation path
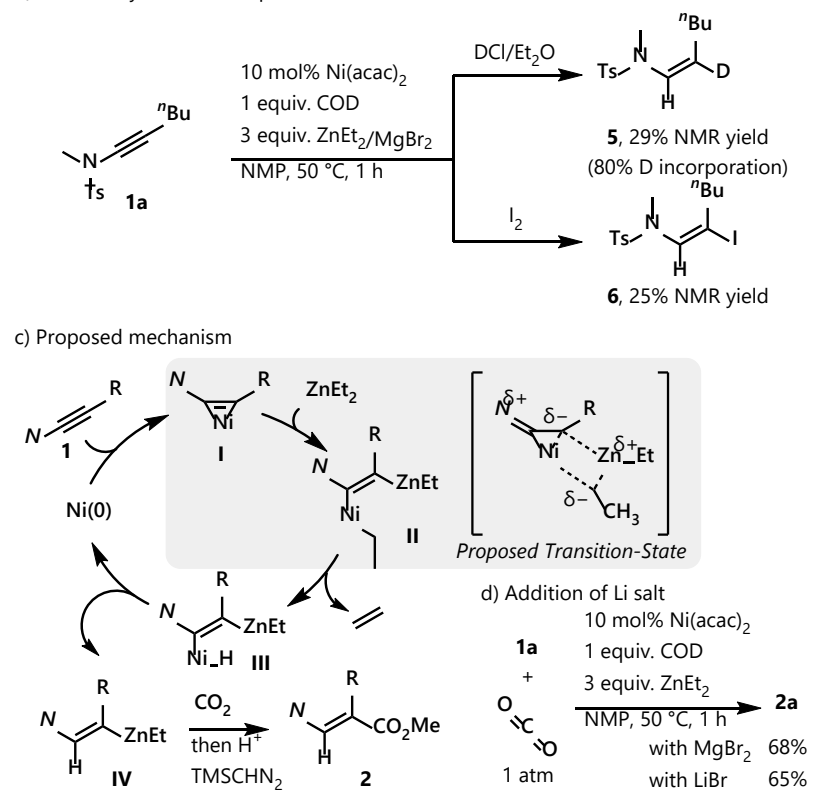

We finally turned our attention to the reaction mechanism. When our standard reaction mixture using an ynamide $1 \mathrm{a}$ was quenched with $\mathrm{DCl} / \mathrm{Et}_{2} \mathrm{O}$, deuterium incorporation was not observed (Figure 2a). This result indicates that the $\alpha$-hydrogen of the product is introduced during the reaction course probably from a $\beta$-hydrogen of diethylzinc. Next, we performed the reaction without $\mathrm{CO}_{2}$ to obtain information on the nucleophilic species that capture $\mathrm{CO}_{2}$. As a result, reduced enamine was obtained in a catalytic manner. In addition, DCl quenching gave $\mathbf{3 a}$ of which the $\beta$-position is deuterated (Figure $2 \mathrm{~b})$. This can be interpreted as generation of an organozinc compound in situ that is protonated by the addition of $\mathrm{HCl}$ or $\mathrm{DCl}$. The addition of iodine gave a corresponding iodinated product 4 of which isolation further supports the existence of a hydrozincation path. Based on these observations and a precedent report, we propose the reaction mechanism illustrated in Figure 2c. ${ }^{11}$ Coordination of $\mathrm{Ni}(0)$, which is added as $\mathrm{Ni}(\operatorname{cod}) 2$ or is generated in situ by reduction of Ni(II) with $\mathrm{ZnEt}_{2}$, with an ynamide results in formation of nickelacyclopropene intermediate I. The electron-donating nature of nitrogen would induce formal anionic charge at the $\beta$-carbon, which might interact with an electropositive zinc atom to facilitate regioselective transmetalation. ${ }^{12}$ In this step, steric repulsion between substituent $\mathrm{R}$ with diethylzinc would have a negative impact on the reaction progress. Meanwhile, an electrondonating tert-butyl group on nitrogen would exert a positive 
effect for the reaction progress as shown in Table 2. The ethyl nickel moiety of intermediate II collapses via $\beta$-hydrogen elimination and a reductive elimination sequence to regenerate $\mathrm{Ni}(0)$ species. The $\mathrm{C}-\mathrm{C}$ bond formation of the resulting vinylzinc species IV with $\mathrm{CO}_{2}$ would be accelerated by the addition of magnesium salt via formation of zincate. It is noteworthy that the addition of $\mathrm{LiBr}$, which is known to form reactive zincate species with an organozinc reagent, also promoted our catalytic carboxylation (Figure $2 \mathrm{~d}$ ). ${ }^{13}$

In summary, we have developed a catalytic $\beta$-carboxylation of ynamides by using $\mathrm{CO}_{2}$ as a $\mathrm{C} 1$ source to afford a precursor of $\beta$ amino acids. Our method used inexpensive and air-stable $\mathrm{Ni}(\mathrm{acac})_{2}$ as a catalyst instead of $\mathrm{Ni}(\mathrm{cod})_{2}$, which was previously added in a stoichiometric quantity. A preliminary mechanistic study suggested generation of a vinylzinc intermediate forging a $\mathrm{C}-\mathrm{C}$ bond with $\mathrm{CO}_{2}$. Further studies to expand our protocol are currently underway.

\section{Funding Information}

Click here to insert sources of funding, grant numbers, etc. Do not repeat the same in the acknowledgment.

\section{Acknowledgment}

Click here to insert acknowledgment text. Funding sources and grant numbers should be given above in the Funding Information section.

\section{Supporting Information}

YES (this text will be updated with links prior to publication)

\section{Primary Data}

NO (this text will be deleted prior to publication)

\section{References and Notes}

(1) Transition-metal catalyzed carboxylation with $\mathrm{CO}_{2}$ : (a) Correa, $\mathrm{A}$ Martin, R. Angew. Chem. Int. Ed. 2009, 48, 6201. (b) Tsuji, Y.; Fujihara, T. Chem. Commun. 2012, 48, 9956. (c) Yu, D.; Teong, S. P.; Zhang, Y. Coord. Chem. Rev. 2015, 293, 279. (d) Börjesson, M.; Moragas, T.; Gallego, D.; Martin, R. ACS Catal. 2016, 6, 6739. (e) Luan, Y.-X. ;Ye, M. Tetrahedron Lett. 2018, 59, 853. (f) Tortajada, A.; Juliá-Hernández, F.; Börjesson, M.; Moragas, T.; Martin, R. Angew. Chem. Int. Ed. 2018 57, 15948. (g) Yang, Y.; Lee, J.-W. Chem. Sci. DOI: 10.1039/C8SC05539D.

(2) Selected examples for nickel-catalyzed carboxylation of alkynes: (a) Louie, J.; Gibby, J. E.; Farnworth, M. V.; Tekavec, T. N. J. Am. Chem. Soc. 2002, 124, 15188. (b) Shimizu, K.; Takimoto, M.; Sato, Y.; Mori, M. Org. Lett. 2005, 7, 195. (c) Mizuno, T.; Oonishi, Y.; Takimoto, M.; Sato,
Y. Eur. J. Org. Chem. 2011, 2606. (d) Fujihara, T.; Horimoto, Y.; Mizoe, T.; Sayyed, F. B.; Tani, Y.; Terao, J.; Sakaki, S.; Tsuji, Y. Org. Lett. 2014, 16, 4960. (e) Wang, X.; Liu, Y.; Martin, R. J. Am. Chem. Soc. 2015, 137, 6476. (f) Wang, X.; Nakajima, M.; Martin, R. J. Am. Chem. Soc. 2015, $137,8924$.

(3) Selected examples for nickel-catalyzed carboxylation of alkenes: (a) Williams, C. M.; Johnson, J. B.; Rovis, T. J. Am. Chem. Soc. 2008, 130, 14936. (b) Lejkowski, M. L.; Lindner, R.; Kageyama, T.; Bódizs, G. É.; Plessow, P. N.; Müller, I. B.; Schäfer, A.; Rominger, F.; Hofmann, P.; Futter, C.; Schunk, S. A.; Limbach, M. Chem. Eur. J. 2012, 18, 14017. (c) Hendriksen, C.; Pidko, E. A.; Yang, G.; Schäffner, B.; Vogt, D. Chem. Eur. J. 2014, 20, 12037. (d) Huguet, N.; Jevtovikj, I.; Gordillo, A.; Lejkowski, M. L.; Lindner, R.; Bru, M.; Khalimon, A. Y.; Rominger, F.; Schunk, S. A.; Hofmann, P.; Limbach, M. Chem. Eur. J. 2014, 20, 16858. (e) Manzini, S.; Huguet, N.; Trapp, O.; Schaub, T. Eur. J. Org. Chem. 2015, 7122. (f) Gaydou, M.; Moragas, T.; Juliá-Hernández, F.; Martin, R. J. Am. Chem. Soc. 2017, 139, 12161. (g) Vavasori, A.; Calgaro, L.; Pietrobon, L.; Ronchin, L. Pure Appl. Chem. 2018, 90, 315. (h) Meng, Q.-Y.; Wang, S.; Huff, G. S.; König, B. J. Am. Chem. Soc. 2018, 140, 3198.

(4) Selected examples for nickel-catalyzed carboxylation of 1,2- and 1,3dienes: (a) Hoberg, H.; Gross, S.; Milchereit, A. Angew. Chem. Int. Ed. Engl. 1987, 26, 571. (b)Takimoto, M.; Mori, M. J. Am. Chem. Soc. 2002, 124, 10008. (c) Takimoto, M.; Nakamura, Y.; Kimura, K.; Mori, M. J. Am. Chem. Soc. 2004, 126, 5956. (d) Takimoto, M.; Kawamura, M.; Mori, M.; Sato, Y. Synlett 2005, 2019. (e) Tortajada, A.; Ninokata, R.; Martin, R. J. Am. Chem. Soc. 2018, 140, 2050.

(5) (a) Saito, N.; Abdullah, I.; Hayashi, K.; Hamada, K. Koyama, M.; Sato, Y. Org. Biomol. Chem. 2016, 14, 10080. (b) Doi, R.; Abdullah, I.; Taniguchi, T.; Saito, N.; Sato, Y. Chem. Commun. 2017, 53, 7720. For examples of biologically active $\beta$-amino acid, see ref 5 a.

(6) Takimoto, M.; Gholap, S. S.; Hou, Z. Chem. Eur. J. 2015, 21, 15218;

(7) We also developed carboxylation of allenamide: Saito, N.; Sugimura, Y. Sato, Y. Synlett 2014, 25, 736.

(8) We have previously conducted DFT calculation of an ynamide which support nucleophilicity at $\beta$-position: Saito, N.; Katayama, T.; Sato, Y. Org. Lett. 2008, 10, 3829.

(9) Wender, P. A.; Smith, T. E.; In Encyclopedia of Reagents for Organic Synthesis, Vol. 2; Paquette, L. A.; Crich, D.; Fuchs, P. L.; Molander, G. A. Ed.; Wiley: Hoboken, 2009, xxx.

(10) Crystallographic data is deposited on The Cambridge Crystallographic Data Centre (CCDC 1906437).

(11) Li, S.; Yuan, W.; Ma, S. Angew. Chem. Int. Ed. 2011, 50, 2578.

(12) This transmetallation step would be formally analogous to protonation of nickelacyclopropene to afford a vinylnickel complex. See: Eisch, J. J.; Ma, X.; Han, K. I.; Gitua, J. N.;Krüger, C. Eur. J. Inorg. Chem. 2001, 77.

(13) (a) Ochiai, H.; Jang, M.; Hirano, K.; Yorimitsu, H.; Oshima, K. Org. Lett. 2008, 10, 2681. (b) Achonduh, G. T.;Hadei, N.; Valente, C.; Avola, S.; O'Brien, C. J. Organ, M. G. Chem. Commun. 2010, 46, 4109. (c) Ohashi, M.; Kambara, T.; Hatanaka, T. Saijo, H.; Doi, R.; Ogoshi, S. J. Am. Chem. Soc. 2011, 133, 3256. (d) Ohashi, M.; Doi, R.; Ogoshi, S. Chem. Eur. J. 2014, 20, 2040. 